\title{
LOS PARQUES ECOARQUEOLÓGICOS EN EL ÁREA MAYA: ALGUNOS ASPECTOS DE SU GESTIÓN
}

\author{
JuAn García Targa \\ Universidad de Barcelona
}

Resumen: La mayor sensibilidad en torno al patrimonio cultural es uno de los rasgos de la sociedad actual. Turistas y ciudadanos de las ciudades demandan mayores grados de protección a los restos del pasado y las autoridades políticas dan respuesta a esa demanda.

En este sentido, los parques ecoarqueológicos son el reflejo de esa nueva oferta en la que muestras del pasado conviven con espacios de descanso con el objetivo de dar a conocer de forma sencilla y divertida periodos anteriores de las ciudades y pueblos.

Palabras clave: patrimonio, gestión cultural, periodos históricos, difusión.

ABSTRACT: The major sensibility around the cultural heritage is one of the traits of the present society. Tourists and citizens ask for the best protection of the past material remains and the political authorities must to reply this question.

In this sense, the eco-archaeological parks reflects this new cultural offers where past evidence remains coexist in repose spaces with the objective to show ancient periods of cities in a simple and enjoyable form.

KEYwORDs: heritage, cultural management, historical periods, diffusion.

ReCEPCIÓN: 29 de octubre del 2007.

ACEPTACIÓN: 8 de octubre del 2008. 



\title{
LOS PARQUES ECOARQUEOLÓGICOS EN EL ÁREA MAYA: ALGUNOS ASPECTOS DE SU GESTIÓN
}

\author{
JuAn García TARGa \\ Universidad de Barcelona
}

\section{Introducción}

Los actuales países abarcados por la cultura maya arqueológica disponen de un patrimonio cultural prehispánico y colonial muy denso y complejo que ha suscitado un intenso trabajo de investigación y conservación. Tradicionalmente, las autoridades nacionales han dado menos relevancia a la difusión amplia de este legado, la cual normalmente se ha circunscrito a los ámbitos especializados.

Los procesos de expansión demográfica en los entornos urbanos y rurales han determinado que restos del pasado e infraestructuras del presente y del futuro se encuentren en un mismo plano. Asimismo, comunidades rurales en zonas deprimidas económicamente pueden aprovechar lo patrimonial en sentido amplio como una posible fuente de recursos económica para su futuro.

Por lo tanto, las instituciones deberían tener como uno de sus objetivos principales la preservación del patrimonio, en coordinación con otros agentes: los promotores inmobiliarios, las empresas turísticas y los intereses económicos locales e internacionales. De la buena interacción entre las instituciones públicas y las entidades privadas dependerá que algunas de las muestras del pasado puedan integrarse en los espacios actuales y, sobre todo, ser explicados a una población que debe convivir con esas ruinas y otorgarles valor como parte de su herencia histórica. "El patrimonio es una prueba evidente de la existencia de vínculos con el pasado. El patrimonio alimenta siempre en el ser humano una satisfacción reconfortante de continuidad en el tiempo y de identificación con una determinada tradición" (Ballart, 2006: 36).

Dentro del marco arqueológico, el proceso de gestión incluye una diversidad de actividades; desde la excavación, consolidación, restauración, musealización y difusión, como estadios previos a la asignación de un valor y a la transformación de un sitio en un referente cultural e histórico importante: "Gestión son las actuaciones programadas con el objetivo de conseguir la conservación de los bienes patrimoniales y un uso adecuado en función de las demandas culturales de la nueva sociedad cambiante" (Ballart y Tresserras, 2001: 15) 


\section{Algunas consideraciones generales}

Hace más de mil años, entre los siglos III y x d.C., la región conformada por los países de Belice, Guatemala, Honduras y los estados mexicanos de Chiapas, Tabasco, Yucatán, Campeche y Quintana Roo conocieron la presencia de un grupo humano cuya concepción cosmogónica sostenía que los dioses los habían creado a partir del maíz: ellos fueron los mayas. Durante el periodo Clásico (250 a 900 d.C.) desarrollaron grandes manifestaciones culturales en todos los órdenes, algunas de ellas como la arquitectura y el arte monumental cuyos ejemplos aún son visibles y están dispersos en las zonas mas recónditas de la selva que persiste en esta zona de aproximadamente 2200 kilómetros cuadrados.

Es alrededor del siglo x comienza la destrucción de las ciudades mayas a raíz del abandono de muchas de ellas a partir del llamado "Colapso maya", fundamentalmente en las Tierras Bajas del Sur (hecho explicado desde diferentes perspectivas, aunque no satisfactorias en todos los casos). Sea como fuere, durante este tiempo ocurre el abandono masivo de grandes sitios como Tikal, Palenque, Copán, Cancuén, Calakmul, entre otros.

Como consecuencia de este abandono, la naturaleza y los agentes atmosféricos han incidido de forma negativa en la conservación de los sitios, originando fracturas y derrumbes en los paramentos, degradación de relieves y pinturas, crecimiento de la vegetación y aparición de hongos. Todo esto ha propiciado la remoción, desprendimiento y, por ende, la destrucción de los materiales constructivos de los palacios y templos.

No obstante, en otros sitios como T’hó, Izamal y Maní, ubicados al norte de la península de Yucatán, la destrucción masiva se acentúa en los siglos posteriores a la Conquista española. En ese momento la Iglesia en su afán de evangelizar desencadena un proceso de destrucción de las construcciones prehispánicas con el fin de eliminar de la mente de los indígenas sus cultos y ceremonias considerados por los frailes como satánicos. Habitualmente el material extraído de las construcciones fue reutilizado para la edificación de los conventos, las iglesias y las casas principales.

La planificación urbana de las ciudades coloniales y modernas también contribuyó al proceso de destrucción de los sitios prehispánicos, pues implicó el uso de los espacios con evidencias materiales anteriores reaprovechando éstos y dañando los rasgos que pudieron definir a esas construcciones precedentes.

Ya entrado el siglo xix, durante el auge henequenero en el norte de la península de Yucatán, la construcción de haciendas continuó con la destrucción de los sitios prehispánicos. Éstas preferentemente se construían cerca de los montículos mayas ante la facilidad de obtención de suficiente material para las casas de los hacendados.

La construcción de carreteras y apertura de unidades de riego durante el siglo $\mathrm{xx}$, y la falta de una política de conservación patrimonial, fueron también causa de destrucción de varios sitios arqueológicos. 


\section{La protección del patrimonio: problemas y objetivos generales}

Los sitios arqueológicos en el área maya son referentes que cuentan una parte de la historia y, en algunos casos, también son testimonios de la crudeza de los procesos de la Conquista (De Vicente, 2006).

En la actualidad, el acelerado crecimiento de las ciudades está desencadenando la expansión de las manchas urbanas, a la vez que acciones como el vandalismo y el saqueo asociados están convirtiéndose en el factor principal de destrucción al poner en riesgo la preservación de los vestigios de los antiguos mayas considerados como valiosas fuentes de información arqueológica. Un caso extremo es el de Kinich Kak-Moo en Izamal de donde, hace pocos años, diversas trituradoras de piedra extrajeron materiales para construcciones actuales.

Por lo tanto, es fundamental la consideración de estas evidencias materiales del pasado en los nuevos planes de desarrollo urbano de las ciudades, de las poblaciones medianas y de las pequeñas. De no ser así, esas muestras del pasado acabarán desapareciendo de forma irremediable (Ordaz, 2006).

A partir de la década de los setenta, esta preocupación se materializó a través de un esfuerzo conjunto realizado por el Instituto Nacional de Antropología e Historia y algunas dependencias municipales y gubernamentales donde se contempla el salvamento e integración de algunos sitios a las ciudades actuales con la creación de los llamados parques arqueoecológicos.

Estos parques empezaron a crearse con la finalidad de integrar los sitios arqueológicos al desarrollo urbano mediante la delimitación de un área relevante dentro de un conjunto más extenso donde el usuario pueda interactuar directamente con los vestigios, brindando una mayor relación de éstos con el entorno inmediato. No obstante, también se ha contemplado la incorporación de proyectos urbanos que favorezcan la protección del medio ambiente mediante la creación de áreas verdes que, a su vez, refuercen el conocimiento de los orígenes y la identidad, así como la difusión del valor histórico, cultural y artístico de la población en la que dichos parques se ubican.

El yacimiento arqueológico, entendido como la manifestación material de una cultura —o forma de vida- desaparecida posee mucho más que un valor estético (ocio) y científico (conocimiento). Estos dos rasgos son a priori, los que llevan a dotar a un yacimiento de una infraestructura necesaria para su visita y los que sirven de cauce para canalizar la relación entre el ciudadano y su patrimonio (Pérez-Juez Gil, 2006: 48).

Consideramos que a la hora de analizar la posibilidad de transformar un espacio dado en un parque ecoarqueológico o espacio patrimonial, se deben considerar diversas variables fundamentales, como las siguientes:

1) Reforzar la legislación que permite proteger los restos arqueológicos dotando a las diferentes administraciones de los recursos humanos y materiales que 
permitan el mantenimiento de esos espacios y sus contenidos, más allá de coyunturas o intereses políticos.

En muchas ocasiones, también en Europa, el mantenimiento de los espacios en condiciones óptimas se reduce a los intervalos de las inauguraciones o visitas al sitio como parte del interés por difundir un esfuerzo de política cultural, quedando olvidados posteriormente. Esta circunstancia es muy común en algunos parques o zonas arqueológicas del área maya integradas o consideradas como parte de una infraestructura más amplia.

2) Incrementar la implicación real de autoridades políticas locales vinculando e interactuando con los grupos vecinales o de la o las colonias más próximas al sitio. En muchas ocasiones se pretende cambiar de forma acelerada una zona tradicionalmente abandonada y transformada en espacio-basurero en un entorno destinado a las gentes de la zona, sin contar con ellos y, por tanto, sin que exista una comunicación fluida entre ambas partes.

3) En relación directa con los dos puntos anteriores, parte de los recursos económicos de los que se disponga deben ser destinados a la difusión de la infraestructura, es decir, del espacio como equipamiento social: no sólo con planos dentro de paneles, sino con una señalización que permita encontrar los diferentes aspectos que se aglutinan en ese espacio y, fundamentalmente, entender el valor patrimonial del mismo.

Este uso social del patrimonio, cada vez más evidente en nuestra sociedad, está en relación directa con una perspectiva no sólo contemplativa de los ejemplos patrimoniales (que nos pueden gustar más o menos desde la perspectiva estética), sino interactiva y de disfrute de esos espacios respetando su singularidad, y asignando un valor a aquellos aspectos relevantes del mismo así como a aquellos valores de singularidad que justifican su conservación e integración en la retícula urbana actual. "El verdadero valor no es tan solo su misma existencia, sino el acceso y el disfrute del mismo por parte de la población" (López de Aguileta, 2000: 92).

4) Los avances en la investigación arqueológica efectuada en la zona deben incorporarse a un discurso explicativo inicial que tienda a transformar en datos comprensibles para el público general una información muchas veces sólo accesible para especialistas en el tema. En la medida que el arqueólogo sea capaz de explicar la relevancia de esos restos, su validez como vía de estudio del pasado, algunos detalles de esa realidad extraña, etcétera, vecinos y visitantes potenciales verán esos restos dentro del parque más como un valor añadido que como un "montón de piedras" o "ruinas" difícilmente comprensibles.

Asimismo, del esfuerzo pedagógico llevado a cabo por el arqueólogo y el equipo de trabajo en un asentamiento dado, del acercamiento a la utilidad de los restos como evidencia fosilizada del pasado, dependerá el grado de implicación 
de los no especialistas y la concientización sobre la importancia de esos restos, la necesidad de su preservación y, más allá de la duración de las campañas, la limpieza sistemática que permita el disfrute de los espacios.

En muchas ocasiones, paseando por supuestos parques arqueológicos urbanos, se observa una área relativamente limpia con estructuras mejor o peor restauradas; en muchas ocasiones con poco mantenimiento como puede apreciarse al observar los grafitos, y sin información alguna, o muy reducida. Esto impide a los vecinos de las casas aledañas interpretar el valor, la función e, incluso, dar una respuesta a por qué tener esos restos en su entorno.

En otros casos urbanos son los vecinos los que aúnan esfuerzos ante la administración con el objetivo de transformar espacios con restos arqueológicos que por ignorancia, por falta de información e interés colectivo, se han transformado en basureros. Lógicamente, esa sensibilidad demostrada por gente que quiere espacios limpios y de valor patrimonial e histórico para sus hijos debe tener una respuesta por parte de esas administraciones que integre las dotaciones económicas para llevar a cabo el trabajo.

En muchos casos, se constata la creación de servicios arqueológicos locales, ya sea en poblaciones medianas o grandes, los cuales (a pesar de lo novedoso de un modelo de gestión más directo e imbricado en la administración) agotan buena parte de sus recursos en sueldos e imagen, dejando en segundo lugar la verdadera finalidad de los mismos como es la preservación del patrimonio y su integración en los espacios urbanos.

En otras ocasiones, proyectos extranjeros y de instituciones nacionales de investigación arqueológica en la zona maya tan sólo extraen información de los sitios. Además, proceden a la restauración total o parcial, siguiendo en muchos casos unos criterios cuando menos poco homogéneos sin generar una información general de calidad que permita estructurar unos guiones explicativos útiles para escuelas, guías, etcétera.

El egoísmo profesional o la apropiación de los sitios por parte de algunos investigadores se manifiesta en la desvinculación de la vertiente social del trabajo, rompiéndose ese vinculo entre el investigador y la sociedad. Para muchos arqueólogos europeos y americanos parece que la elaboración de publicaciones no científicas (es decir, no técnicas), supone un desprestigio para ellos mismos y su equipo. El resultado es evidente: buena parte de las ponencias que se presentan a congresos, coloquios, mesas redondas, simposios y revistas son de carácter puramente descriptivo, de piezas, medidas o calidades artísticas de elementos, sin generarse interpretaciones que permitan incluso a los colegas entender hacia donde se orienta la investigación de ciertos asentamientos relevantes (García Targa, 2010).

En este sentido, hace unos veinte años el autor de este artículo asistió a un congreso internacional sobre el vino en época romana en Badalona (Barcelona, España). De un total de casi cien ponencias, tan sólo en un caso alguien se dignó a analizar cómo podía ser el vino según las fuentes escritas clásicas, cómo se 
gestionaba su transporte o qué preferencias tenía la gente. La práctica totalidad de las ponencias y comunicaciones versaban sobre los recipientes contenedores, sus formas, arcillas, cocciones; sin duda aspectos interesantes, pero descripciones puras, sin que estos referentes analíticos sirvieran para dar un paso hacia una interpretación integral de aspectos sociales, culturales, etcétera. En muchos de los congresos especializados en cultura maya o en Mesoamérica en general, se tiende también a perder la perspectiva de la vertiente antropológica, humana, de los trabajos arqueológicos que se llevan a cabo.

\section{Modelos de trabajo en los parques ecoarqueológicos: rasgos definitorios}

De acuerdo con De Vicente (2006) existen tres posibilidades de integración y aprovechamiento de los sitios arqueológicos:

1) Sitio abierto al turismo;

2) Sitio que forma parte de un recorrido ecoturístico;

3) Vestigio integrado a un área verde.

El primer modelo es el más habitual en el área maya, que dispone de numerosos ejemplos como: Ek Balam, Uxmal, Chichén-Itzá (figura 1), Oxkintok, Edzná, Mayapán, Yaxchilán, entre otros. Se trata, en la mayoría de los casos, de sitios

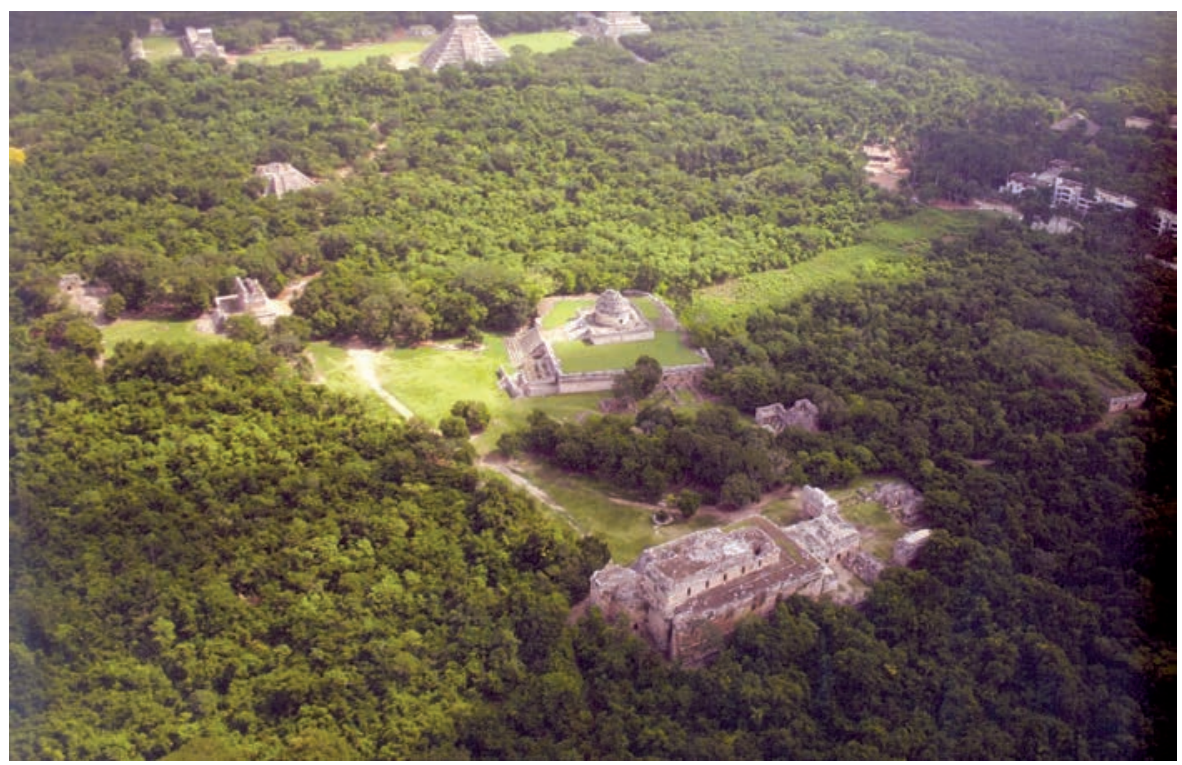

Figura 1. Vista aérea de Chichén-Itzá (Yucatán). Imagen tomada de Tradiciones del Sol 
abandonados por la población y que disponen de unos restos patrimoniales importantes dentro de un contexto natural que permite estructurar un cierto discurso explicativo referente a ellos. No obstante, dentro de este apartado se incluirían sitios muy diversos en extensión, infraestructura, recursos económicos y humanos.

El segundo podría corresponder a modelos como el de la ruta Puuc, desarrollada desde hace años en la parte suroeste del estado de Yucatán. Esta oferta hace compatible el disfrute del entorno natural y de los modelos urbanos mayas de finales del clásico en esta zona.

El tercero parece corresponder al modelo más tradicional de parque. Se trata de un espacio urbano que se ha acondicionado para la convivencia de restos arqueológicos dentro de unos senderos que permitan el acercamiento a la variedad natural de la zona. Ejemplos de este modelo serían los diferentes espacios que se encuentran dentro de la mancha urbana de la ciudad de Mérida.

Sin embargo, el tercer modelo parece responder por su enunciado a restos sencillos e incluso aislados, quizás de poca o reducida entidad, que como tal se le integra para no ser destruido. No obstante, ¿dentro de qué apartado se encontrarían evidencias de sitios como Izamal, Aké, Acanceh (figura 2), Chiapa de Corzo, Dzilam o Caucel?; en estas poblaciones los restos monumentales impregnan la población actual. En este sentido, pueden considerarse tanto sitios

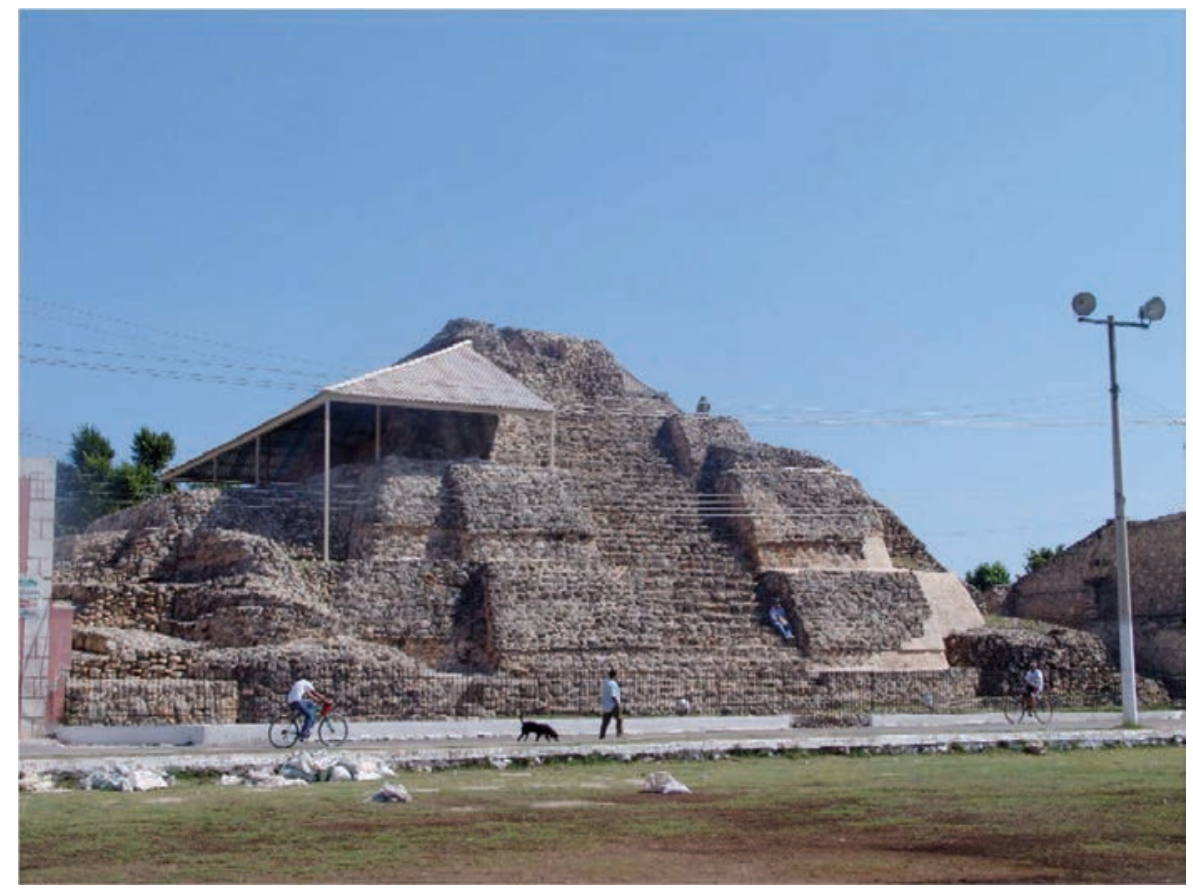

FigurA 2. Estructura principal del sitio de Acanceh (Yucatán, México). Fotografía del autor 
abiertos al público, como sitios que forman parte de un recorrido ecoturístico; incluso, el hallazgo de evidencias aisladas más o menos cercanas a espacios con mayor densidad de estructuras pueden ser integradas dentro del tercer apartado definido por De Vicente (2006).

Cuando se analizan asentamientos no urbanos, como el caso de Tikal, Calakmul, Copán o Palenque, ¿a qué tipo de modelo pertenecen? Al otorgárseles la denominación de Reserva de la Biosfera a algunos, puede parecer claro que se deben encuadrar dentro del apartado de sitio que forma parte de un recorrido ecoturístico, dado que supera cualquiera de las otras catalogaciones con base en lo extenso y complejo de estos conjuntos.

No obstante, son precisamente las dimensiones de estos espacios patrimoniales en sentido extenso los rasgos que a nuestro juicio evitan la clasificación de los mencionados sitios como parques. Este término parece corresponder claramente a áreas más reducidas del territorio, y mayoritariamente localizadas en contextos urbanos o rurales, y no a grandes complejos turísticos estructurados con base en unos vestigios impresionantes con un contexto natural privilegiado.

\section{Estudios de caso}

Parques arqueológicos de Mérida: un ejemplo urbano

El objetivo de estos parques es renovar las evidencias arqueológicas de la antigua ciudad dentro de unos espacios naturales importantes que permitan dotar a la gente de entornos favorables para el descanso, el conocimiento y la cohesión social a través de la protección, el respeto y el uso racional del patrimonio en sentido amplio (figura 3).

El parque recreativo de Oriente y el Parque del Fraccionamiento las Granjas y el Vergel II, son espacios que ofrecen la posibilidad de establecer un primer circuito arqueológico urbano de interés local, turístico y cultural. La limpieza, reforestación y mantenimiento constante de zonas, una señalización con base a cédulas que contengan información principal de los edificios restaurados, un servicio especial de transporte público desde el centro urbano, así como un servicio de visitas guiadas, son aspectos que podrían impulsarse a corto plazo para dar a conocer el pasado maya de la ciudad y que muy probablemente podría contar con el beneplácito y apoyo económico del sector turístico local (Ligorred Perramon, 1998: LI).

Sin duda, como siempre, las intenciones o directrices son interesantes, pero el problema está en su puesta en práctica, siendo imprescindible para ello disponer de los recursos económicos necesarios. En la referencia antes citada se mencionan algunos de los aspectos importantes y que, de hecho, son comunes a los proyectos de musealización de espacios arqueológicos. No obstante, la visualización de algunos de los parques de la ciudad de Mérida no responden 


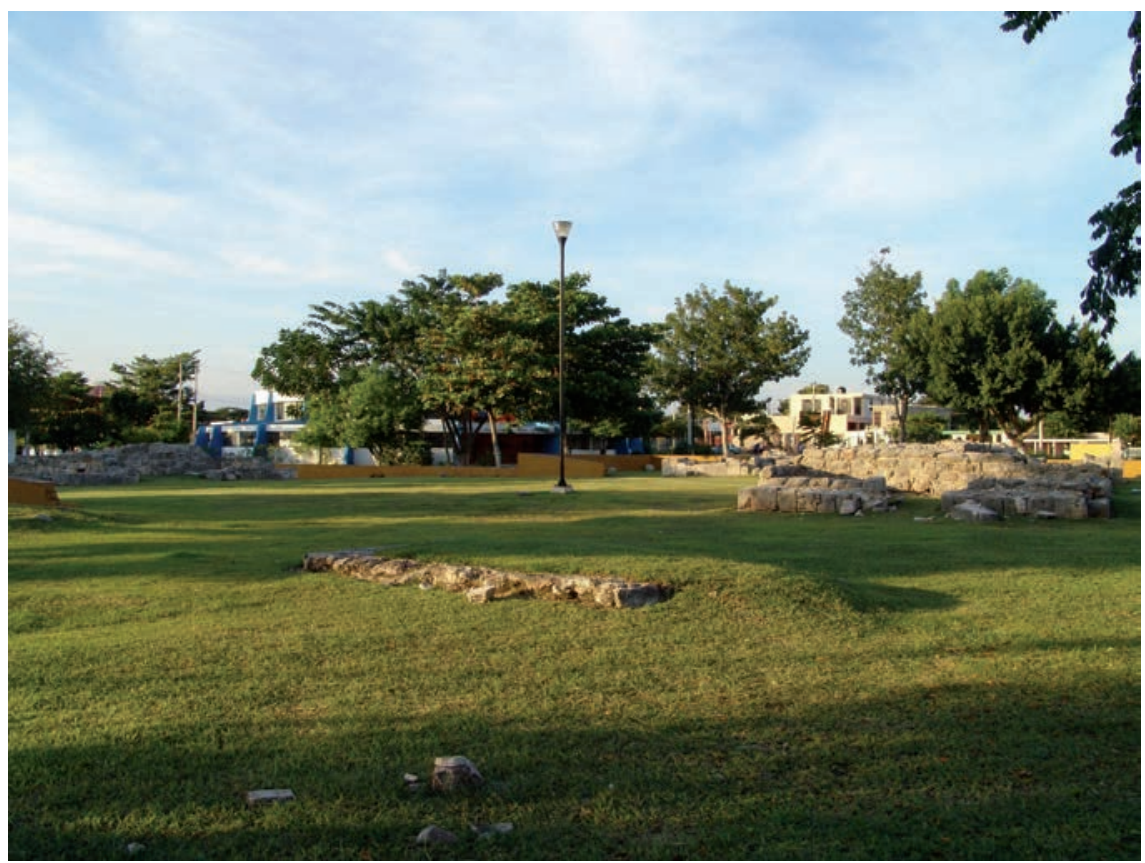

Figura 3. Vista general del parque arqueológico de Dzoyila (Mérida, Yucatán). Fotografía del autor

en buena medida a esta propuesta de intenciones de hace unos años, dadas las carencias infraestructurales comunes a otras muchas ciudades.

La transformación de unos restos arqueológicos aparecidos durante un salvamento en un parque potencial debe responder: 1) a la relevancia objetiva de los mismos dada su significación dentro del registro material de la zona y su representatividad cultural; 2) a la posibilidad de llevar a cabo un cambio en el proyecto de obra en curso que permita hacer compatible el objetivo de la obra y la preservación y difusión de esas evidencias históricas; 3) y a la disponibilidad económica para los trabajos de consolidación, restauración y acondicionamiento de los mismos y su mantenimiento a lo largo del tiempo.

Las consideraciones técnicas son coordinadas por el Instituto Nacional de Antropología e Historia en conjunción con el Ayuntamiento de Mérida a través del Departamento de Patrimonio Arqueológico y Natural del Municipio (DPANM), pero el dispendio económico es asumido mayoritariamente por la promotora de la obra a cambio de permutas y ventajas fiscales o mejoras en condiciones para otras obras, además del reconocimiento social de su participación en proyectos relacionados con el patrimonio colectivo (figura 2). Es decir, como sucede las más de las veces en muchos países, es el capital privado el que acaba sufragando el patrimonio cultural quedando luego su mantenimiento a expensas de los presupuestos municipales, estatales y federales. 
El problema básico es disponer de los fondos que permitan dar mantenimiento a esos espacios, tenerlos en condiciones para ser visitados, generar líneas de trabajo que den a conocer esas zonas y diseñar actividades que permitan al público potencial interactuar en ese entorno, más allá de ver unos restos que, en la mayoría de los casos, son de difícil comprensión (figura 4).

En muchas ocasiones, en España, parte de los presupuestos de algunas obras muy costosas se dedican por ley a inversiones patrimoniales de los municipios afectados, el llamado $1 \%$ cultural aplicable a proyectos de arqueología, restauración o construcción de equipamientos culturales que se consideren necesarios. Tal es el caso de las carreteras. Es habitual contemplar cómo los ayuntamientos piden la conservación de ciertos restos arqueológicos de dudosa relevancia en algunas ocasiones, aunque ello suponga el incremento del presupuesto de la obra, además de los retrasos de la misma. Todo ese movimiento de intereses radica en poder administrar esas muestras patrimoniales, encargándose de su mantenimiento y "explotación". No obstante, cuando finalmente se decide que los restos pasen a la jurisdicción del municipio y sea el ayuntamiento quien los gestione, la falta de interés al ver que generan gastos de mantenimiento y de explotación, en muchos casos, transforma a esas evidencias del pasado en espacios cubiertos de vegetación, progresiva degradación y transformación de la zona en espacio de acumulación de basura.

Por lo tanto, sería fundamental prever el mantenimiento de esas "cápsulas culturales al aire libre" y su costo anual como un gasto periódico, independientemente del consistorio municipal de cada periodo. De no ser así, sería preferible tapar los restos, no programar nuevos parques ecoarqueológicos, dado que el abandono de algunos de los ya existentes supone un descrédito para los organismos municipales, además de la incomprensión por parte de los ciudadanos que ven sus impuestos mal invertidos y su calidad de vida desatendida, después de promesas de mejora de sus entornos.

Pasemos a analizar algunos modelos de trabajo tan sólo mediante algunas breves pinceladas:

El modelo de Oxwatz

Tekal de Venegas, Yucatán, México (García Targa et al., 2007: 397-408)

El origen de este parque que todavía está en fase embrionaria reside en una propuesta surgida desde la propia población, como estrategia para compensar las deficiencias económicas de la zona y de sus pobladores. El lógico interés por la puesta en marcha de esta iniciativa incide en la generación de ideas, la búsqueda de recursos y la organización de todas aquellas personas interesadas en participar en esta apuesta por la generación de proyectos locales.

A través de algunas ayudas de diferentes dependencias administrativas del estado y federales, se han ido mejorando aspectos relacionados con la transformación de una gran extensión de terreno (412 ha) en una oferta de turismo 


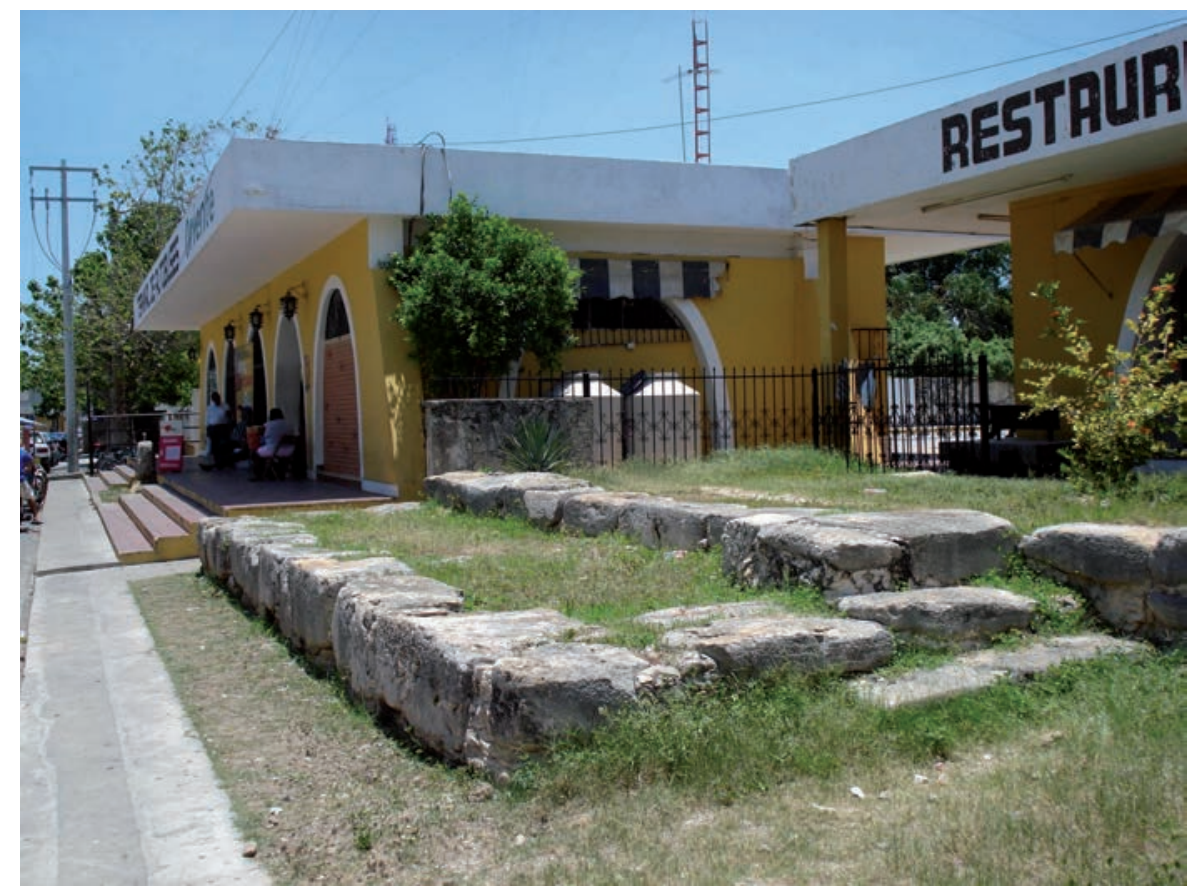

Figura 4. Vista general de una de las estructuras del sitio maya de Izamal (Yucatán).

Fotografía del autor

cultural; se integra la contemplación y el estudio del entorno natural y de los restos de tres asentamientos mayas que se localizan en esta zona.

Lógicamente, la afluencia de turistas nacionales e internacionales permitirá el mantenimiento de los diferentes grupos de trabajo dedicados a la limpieza y mantenimiento de los caminos de acceso y de los senderos interiores, la construcción de palapas destinadas a los servicios de información, servicio y descanso de los visitantes, etcétera (figura 5). Paralelamente facilitará la formación de los guías, la disponibilidad de los materiales que permitan la observación de las aves, o los recorridos en bicicleta, así como una primera señalización provisional y la elaboración de una página web que permita abrir el proyecto al exterior.

El progresivo conocimiento del sitio permitirá avanzar en la consolidación de las estructuras y generar un discurso riguroso pero didáctico sobre la importancia histórica de este asentamiento que se encontraba dentro de la órbita de Izamal.

Este modelo de parque es sin duda mucho más modesto que sitios con la repercusión mediática de Chichén Itzá, Palenque, Uxmal o Tikal. No obstante, representa un esfuerzo por diversificar la oferta que no únicamente se reduce a visitar los restos arquitectónicos, sino a poder participar de forma más activa con el entorno natural, recorrer ciertos espacios a pie o en bicicleta, observar de forma activa la naturaleza o pernoctar en entornos naturales acondicionados. 


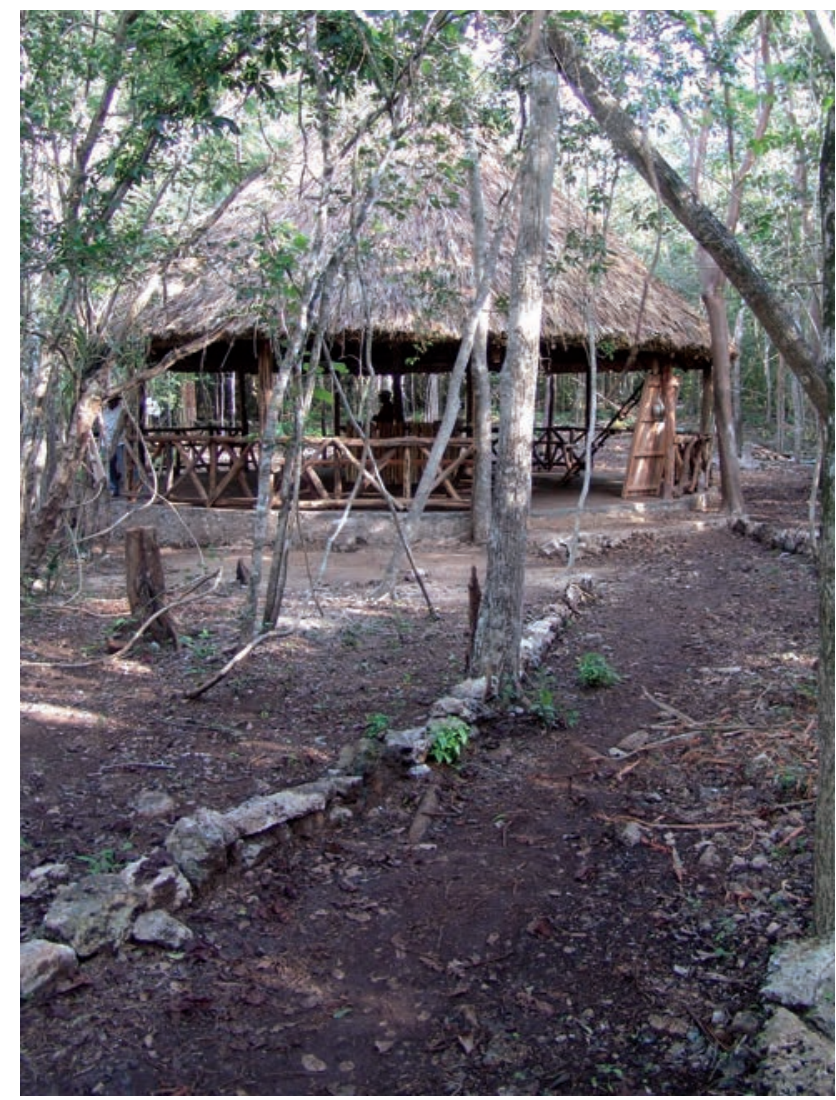

Figura 5. Palapa de recepción a los visitantes del parque Oxwatz (Tekal de Venegas, Yucatán). Fotografía del autor

\section{El modelo de Tikal}

El Petén, Guatemala (Coe, 1988; Muñoz Cosme y Vidal Lorenzo, 2003)

El asentamiento prehispánico está documentado desde mediados del siglo xIx cuando se llevó a cabo una primera expedición, si bien el sitio era conocido por algunos misioneros españoles desde mediados del siglo xvII.

El Parque Nacional Tikal se creó el año 1955 bajo la responsabilidad del Instituto de Antropología e Historia, y se constituyó como la primera área protegida de Guatemala. Posteriormente fue reconocido, en 1979, como Patrimonio Mundial por la unESCO. El parque cuenta con una extensión de $575.83 \mathrm{~km}$.

En 1970, la Secretaría de Planificación Económica crea el Proyecto Administración del Parque Nacional Tikal con el propósito de darle seguimiento a la conservación de las obras realizadas por la Universidad de Pensilvania y Fo- 
mento y Desarrollo de El Petén (FYDEP), así como para habilitar otras áreas para el turismo.

En 1972 se elabora el primer Plan Maestro para la Protección y Uso del Parque coordinado por la Secretaría del Consejo Nacional de Planificación Económica y la colaboración del Instituto de Antropología e Historia y el Instituto Guatemalteco de Turismo. Aspectos importantes de este plan fueron: 1) la construcción del aeropuerto de Santa Elena, el actual Centro de Visitantes; 2) el traslado de la aldea Tikal hacia Ixlú; y 3) la pavimentación de la carretera Flores-Tikal. En la puesta en práctica del plan también colaboró el Servicio de Parques Nacionales de los Estados Unidos.

La misma secretaría en 1974 diseña el Proyecto de Desarrollo Turístico, con el fin de apoyar el desenvolvimiento del potencial turístico de Tikal, así como para proteger las ruinas y prevenir daños ecológicos en el área de influencia del parque.

La relevancia patrimonial del parque, desde las perspectivas monumental y biológica, determinaron que la unEsco lo declarase el año 1979 como primer sitio de Patrimonio Mundial Mixto de la Humanidad.

El año 1989 el Congreso de la República crea el Sistema Guatemalteco de Áreas Protegidas y el siguiente se crea la Reserva de Biosfera Maya, definiendo al Parque Nacional Tikal como una de las zonas núcleo de dicha reserva. Entre otros aspectos se le ratifica además la administración del área al Instituto de Antropología e Historia. En el año de 1993, el IDAEH transfiere la administración del sitio arqueológico de Uaxactún al Parque Tikal extendiéndose el territorio y ampliando, a su vez, las competencias administrativas del parque.

Durante el año 2002 se realizó una nueva definición de los límites con el fin de inscribirlo en Registro de la Propiedad Inmueble y aclarar su situación jurídica. El aval legislativo reconocía este nuevo espacio más extenso e implicaba además que el Instituto de Antropología e Historia se encargaría del mantenimiento y la gestión (figura 6).

Los objetivos del parque son diversos: 1) proteger los bienes culturales y arqueológicos del Parque Nacional Tikal, a través de la investigación y la conservación; 2) conservar la diversidad biológica y los procesos ecológicos que ocurren en el espacio ocupado mediante la protección, la investigación y el manejo; 3) desarrollar el potencial educativo y de uso público de los recursos culturales y naturales generando los mecanismos y recursos correspondientes; y 4) involucrar a las comunidades adyacentes al parque para promover el mantenimiento y la promoción.

\section{El modelo de Xcaret}

Quintana Roo, México

Xcaret, originalmente llamado Polé, fue un puerto prehispánico fechado en el periodo Posclásico Tardío (1400-1517 d.C.). A esta caleta llegaban las mercancías 


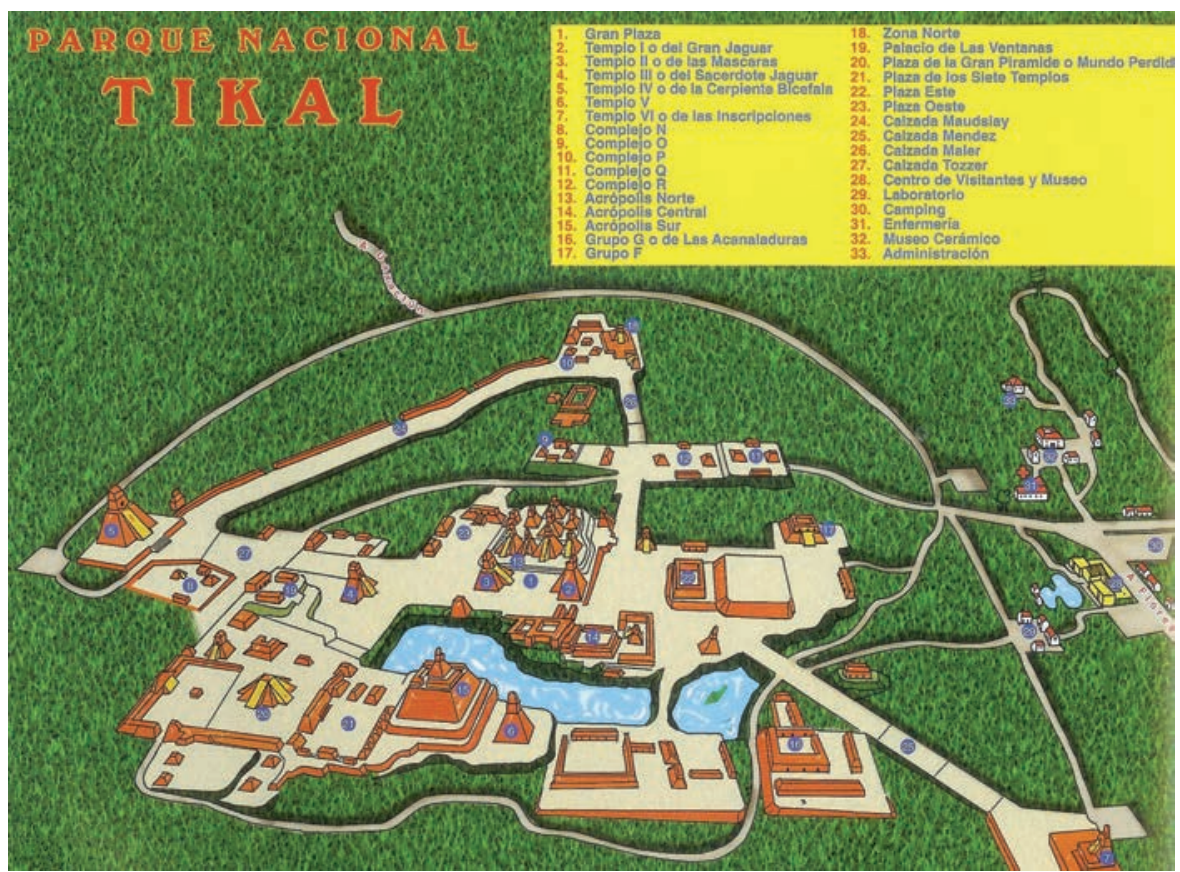

Figura 6. Plano gráfico del Parque Nacional Tikal (Petén, Guatemala).

Tríptico de mano del sitio de Tikal

que los mayas intercambiaban con otros pueblos, por lo que probablemente fue uno de los centros marítimos comerciales más importantes de la zona.

El origen del parque de Xcaret se remonta al año de 1990, cuando fue inaugurado durante la administración del gobernador Miguel Borge como parte de los intereses de un pequeño grupo de empresarios en transformar un espacio natural magnífico en modelo respetuoso y de difusión del entorno natural.

Durante los trabajos relacionados con la delimitación de la zona se puso de manifiesto la riqueza natural y patrimonial del sitio, implicando la necesidad de integrarlas dentro del proyecto final. De este modo, coordinados con el INAH, se procuró consolidar todos los vestigios mayas y estructuras que se documentaron dentro de esta área.

No obstante, con el paso del tiempo este interés inicial se ha visto desviado ante la mala difusión del sitio arqueológico, puesto que se obtiene mayor rentabilidad económica y significación del área comercial turística y no de la arqueológica. La principal problemática al respecto es que no se informa con claridad al turista que no es obligatorio adquirir el pase de entrada al parque recreativo cuyo costo es de casi 700 pesos por adulto para poder acceder al sitio arqueológico, pues existe una cuota que no rebasa los 50 pesos para visitar únicamente los vestigios resguardados por el INAH. 
Esto ha provocado que el visitante llegue sólo a visitar la zona comercial, sin enterarse de que existen vestigios arqueológicos o, lo que es peor, pensando que éstos son parte de la escenografía de la zona turística comercial haciéndoles creer que se encuentran en lo que algunos arqueólogos llaman el "Disneyland Mexicano" (Garduño Argueta, 2010).

Los terrenos donde se ubica el parque son propiedad privada desde 1984 cuando Promotora Xcaret compró el rancho donde se ubica el asentamiento prehispánico. Fue en 1986 cuando dieron inicio los trabajos arqueológicos. La documentación y restauración de restos arqueológicos del asentamiento prehispánico y colonial fueron sufragadas en su práctica totalidad por el parque y coordinadas por el INAH.

El parque dispone de estacionamiento, centro de información, cajero automático, tiendas de recuerdos, paramédicos y enfermería, duchas, espacios de descanso con hamacas y camas, casilleros, posibilidad de alquilar sillas de ruedas, toallas, equipos de submarinismo, etc. Es decir, la empresa destinada al entretenimiento en un entorno excelente dispone de todos aquellos requisitos que deben responder a la normativa nacional e internacional de parques, además de formar parte de la oferta de los diferentes paquetes turísticos de la Riviera Maya.

\section{Consideraciones finales}

Las cada vez mayores y lógicas demandas sociales de calidad de vida en espacios urbanos y rurales explican en buena medida la creciente sensibilidad social en torno al patrimonio en sentido amplio, como bien colectivo, importante para la cohesión social.

En relación con ello, destaca la proliferación de espacios recreativos que integran el entorno natural junto con los vestigios arqueológicos, cuya finalidad es la difusión de los valores artísticos, culturales e históricos no solo de la población cercana a ellos, sino también a nivel internacional como en cada uno de los casos mencionados a lo largo de este trabajo.

Esa popularización o acercamiento de la cultura a la mayoría de la población no debería ser incompatible con el establecimiento o la continuidad de programas de investigación que sirvan para profundizar más los conocimientos que se tengan sobre cada uno de los lugares.

La creación de los parques arqueológicos y arqueoecológicos en el área maya, en general, tiene la finalidad de integrar los antiguos vestigios y su entorno al crecimiento de las ciudades. No obstante, es de suma importancia considerar las causas de sus éxitos y fracasos. Debe dárseles mantenimiento (como en el caso de los vestigios pequeños aunque no menos importantes), pero sobre todo difusión y protección, no sólo enfocadas en el aspecto turístico y comercial (también importante), sino en los aspectos arqueológicos e históricos que conformarían la parte medular de estos proyectos. 
La carencia de este seguimiento activo y de inversión en las diferentes vertientes de estas ofertas para el ocio y la difusión de la cultura debería ayudar a valorar los bienes patrimoniales como algo positivo e incluso divertido según los enfoques que se establezcan, y no como sucede en muchos casos: incrementar el riesgo de su destrucción y pérdida en manos del mismo turismo.

Finalmente, los beneficios de esos nuevos espacios patrimoniales deberían repercutir en las poblaciones o colonias cercanas. Además, la presencia de esa muestra material repercute en el conocimiento de los orígenes y en el fortalecimiento de la identidad, así como en la integración y la creación de espacios de recreación y descanso.

\section{BIBLIOGRAFÍA}

Ballart, Josep

2006 El patrimonio histórico y arqueológico: valor y uso. Barcelona: Ariel Patrimonio.

Ballart, Josep y Jordi Joan Tresserras

2001 Gestión del patrimonio cultural. Barcelona: Ariel Patrimonio.

Coe, William

1988 Tikal. Guía de las antiguas ruinas mayas. Filadelfia: University of Pennsylvania, The University Museum.

De Vicente, Esteban

2006 "Resistencia y proteccion de los sitios arqueológicos del municipio de Mérida”, Memorias del Segundo Anuario de Investigación Sobre Conservación, Historia y Patrimonio Arquitectonico y Urbano. Blanca Paredes Guerrero (ed.). México: Universidad Autónoma de Yucatán, Facultad de Arquitectura, 235-236.

García Targa, Juan

2010 "Patrimonio arqueológico yucateco: algunos aspectos y sugerencias en torno a la gestión y difusión”, I Congreso sobre Patrimonio Cultural en México: Problemática actual y propuestas para su intervención. México: Universidad Autónoma de Yucatán.

García Targa, Juan, Manuel Jesús Chan Chim, José Antonio Ceballos Uc, Francisco Javier García Marqués y Eduardo Puga Salazar

2007 "Proyecto Oxwatz (Tekal de Venegas, Yucatán, México): líneas generales del parque eco-arqueológico", Los Investigadores de la Cultura Maya, 15 (II): 397408. México: Universidad Autónoma de Campeche.

Garduño Argueta, Jaime

2010 "La mercantilización del patrimonio arqueológico se hace por ignorancia y avaricia”, Ier Congreso sobre Patrimonio Cultural en México: problemática actual 
y propuestas para su intervención. México: Universidad Autónoma de Yucatán.

Ligorred Perramon, José

1998 T’Ho, la Mérida ancestral. México: H. Ayuntamiento de Mérida, Dirección de Desarrollo Urbano.

Lopez de Aguileta, Iñaki

2000 Cultura y Ciudad. Manual de política cultural municipal. México: Trea.

Muñoz Cosme, Gaspar y Vidal Lorenzo, Cristina

2003 "El impacto del turismo en las ruinas de Tikal, Guatemala”, II Congreso Internacional sobre Musealización de Yacimientos Arqueológicos. Nuevos conceptos y estrategias de gestión y comunicación. Barcelona: Ayuntamiento de Barcelona, Instituto de Cultura, 347-351.

Ordaz, Marisol

2006 "Problemas de los parques arqueoecológicos de la ciudad de Mérida", Memorias II. Anuario de Investigación sobre conservación, historia y crítica del patrimonio arquitectónico y urbano. México: Universidad Autónoma de Yucatán, Facultad de Arquitectura, 209-216.

Paredes Guerrero, Blanca (coord.)

2006 Memorias II. Anuario de Investigación sobre conservación, historia y crítica del patrimonio arquitectónico y urbano. México: Universidad Autónoma de Yucatán, Facultad de Arquitectura.

Pérez-Juez Gil, Amalia

2006 Gestión de patrimonio arqueológico. El yacimiento como recursos turístico. Barcelona: Ariel Patrimonio.

Tradiciones del Sol: un viaje fotográfico a Yucatán

2006 Catherine Harrison Wiita, Amy Barsky, Isabel Hawkins, José Huchim Herrera y Domingo Dzul Poot (trads.). Berkeley: National Aeronautics and Space Administration, Sun-Earth Connection Education Forum / University of California, Berkeley / Instituto Nacional de Antropología e Historia. 
